\title{
CARACTERÍSTICAS FÍSICAS E QUÍMICO-NUTRICIONAIS DE FRUTOS DE PEQUIZEIRO (Caryocar coriaceum WITTM.) EM POPULAÇÕES NATURAIS DA REGIÃO MEIO-NORTE DO BRASIL ${ }^{1}$
}

\author{
KLÉGEA MARIA CÂNCIO RAMOS², VALDOMIRO AURÉLIO BARBOSA DE SOUZA
}

RESUMO - Este trabalho teve como objetivo avaliar a variabilidade de características físicas e químiconutricionais de frutos de seis populações de pequizeiro de ocorrência nos Estados do Maranhão e Piauí (região Meio-Norte do Brasil). Os frutos foram coletados no estádio de maturação (frutos caídos no chão), na safra de 2008. Analisaram-se as seguintes características físicas do fruto: massa média, massa média da casca, massa média do caroço, massa média da amêndoa, percentagem de polpa, relação comprimento/ diâmetro médio do fruto, relação comprimento/diâmetro médio do caroço, relação comprimento/diâmetro médio da amêndoa e espessura média da casca. Na polpa e na amêndoa, foram analisadas as características químico-nutricionais: umidade, gordura, proteína bruta, fibra bruta, cinzas, carboidratos totais, energia e minerais ( $\mathrm{P}, \mathrm{K}, \mathrm{Ca}, \mathrm{Mg}, \mathrm{Mn}, \mathrm{Cu}, \mathrm{Zn}$ e $\mathrm{Fe})$. Os dados foram submetidos à análise de variância, e as médias das populações foram comparadas pelo teste de agrupamento Scott-Knott a 5\%. Observou-se elevada variabilidade fenotípica entre as populações para a maioria dos caracteres analisados. Ambas, polpa e amêndoa, mostraram-se ricas em termos nutricionais, sendo a amêndoa, porém, bem mais rica. Em média, a população de Alto Longá, no Piauí, é uma promissora fonte de variabilidade para a maioria dos caracteres físicos e químico-nutricionais estudados.

Termos para indexação: Frutífera nativa, Caryocar coriaceum, recursos genéticos, variabilidade fenotípica.

\section{PHYSICAL AND CHEMICAL-NUTRITIONAL CHARACTERISTICS OF PEQUI FRUITS (Caryocar coriaceum WITTM.) IN NATURAL POPULATIONS OF THE MID-NORTH REGION OF BRAZIL}

\begin{abstract}
The objective of this work was to evaluate physical and chemical-nutritional characteristics of fruits from six pequi populations of natural occurrence in the states of Maranhão and Piauí (Mid-North region of Brazil). Fruits were collected at the maturity stage (fruits lying on the ground), at the 2008 harvest. The following physical characteristics of fruits were analyzed: average mass, peel average mass, stone average mass, kernel average mass, pulp percentage, fruit length/fruit mean diameter ratio, stone length/ stone mean diameter ratio, kernel length/kernel mean diameter ratio and peel average thickness. In the pulp and kernel the following chemical-nutritional characteristics: moisture, fat, crude protein, crude fiber, ash, total carbohydrates, energy and minerals $(\mathrm{P}, \mathrm{K}, \mathrm{Ca}, \mathrm{Mg}, \mathrm{Mn}, \mathrm{Cu}, \mathrm{Zn}$ and $\mathrm{Fe}$ ) were analyzed. The data were submitted to the variance analysis and population means were compared by Scott-Knott grouping test at $5 \%$. It was observed a high phenotypic variability among populations for most analyzed traits. Both pulp and kernel are rich in nutritional terms, being the kernel, however, much richer. On average, the population of Alto Longá, from the state of Piauí, is a promising source of variability for most physical and chemicalnutritional characters studied.
\end{abstract}

Index terms: Native fruit tree, Caryocar coriaceum, genetic resources, phenotypic variability.

\footnotetext{
${ }^{1}$ (Trabalho 118-10). Recebido em: 10-05-2010. Aceito para publicação em: 05-11-2010. Parte da Dissertação de Mestrado do primeiro autor.

${ }^{2}$ Bióloga, MSc. em Desenvolvimento e Meio Ambiente/TROPEN/PRODEMA/UFPI, Av. São Sebastião, 2819, CEP 64.202-020, Parnaíba-PI. E-mail: klegea@hotmail.com

${ }^{3}$ Eng. Agr., PhD., Embrapa Meio-Norte, Av. Duque de Caxias, 5650, CEP: 64.006-220, Teresina-PI. E-mail: valdo@cpamn.embrapa.br (in memoriam).
} 


\section{INTRODUÇÃO}

O Meio Norte é um dos quatro domínios geoambientais do Nordeste Brasileiro, sendo constituído pelos Estados do Maranhão e do Piauí em uma zona de transição entre a Amazônia e o Sertão, com pluviometria anual entre 1.000 e $2.500 \mathrm{~mm}$ (REBOUÇAS, 1997).

Caracteriza-se pela diversidade de ecossistemas e pela biodiversidade, com destaque para as espécies frutíferas nativas, como, por exemplo, o bacurizeiro (Platonia insignis Mart.) e o pequizeiro (Caryocar coriaceum Wittm.), cujos frutos são amplamente utilizados pelas populações locais. Além do Meio-Norte, a espécie $C$. coriaceum ocorre também nos Estados do Ceará, Bahia, Pernambuco e Goiás (LORENZI, 1992).

O pequizeiro pertence à família Caryocaraceae e ao gênero Caryocar, que engloba 16 espécies, das quais 12 têm ocorrência no Brasil. A planta apresenta porte arbóreo, que atinge em média de 6 a $8 \mathrm{~m}$ de altura, e suas inflorescências produzem um número variado de flores (hermafroditas e actinomorfas), grandes (5,0 a 7,5 cm de diâmetro) e de cor variando de esverdeada a branca, e com antese crepuscular (ARAÚJO, 1995). Estudos realizados com C. brasiliense e $C$. villosum, indicam que as espécies desse gênero são fortemente alógamas (GRIBEL; HAY, 1993; MARTINS; GRIBEL, 2007), onde pequenos morcegos nectarívoros (Glossophaga socicina e Anoura geoffroyi) são os principais polinizadores, e a protandria e a hercogamia (separação espacial de anteras e estigmas) funcionam como principais mecanismos contra a autogamia (GRIBEL; HAY, 1993). Porém, a despeito da alogamia acentuada, a autopolinização pode ocorrer em pequena proporção (GRIBEL; HAY, 1993; MARTINS; GRIBEL, 2007). Em geral, a floração ocorre entre agosto e novembro, dependendo da região de ocorrência, e a maturação dos frutos leva de três a quatro meses após a polinização, com baixa taxa de vingamento de frutos (ARAÚJO, 1995). Porém, ainda assim, segundo esse autor, uma planta de pequi pode produzir de 500 a 2.000 frutos/safra.

O fruto de pequi é uma drupa de forma depresso-globosa, com epicarpo coriáceo, carnoso e de coloração verde-clara a levemente amarelada quando maduro, apresentando endocarpo espinhoso. Suas dimensões variam de 4-7 cm de altura e 6-8 $\mathrm{cm}$ de diâmetro, com a massa média alcançando aproximadamente $120 \mathrm{~g}$, mas com variação de 100 a 220 g. A polpa é oleaginosa, farinácea e tem consistência pastosa, apresenta coloração variando do amarelo-creme ao amarelo-intenso e, algumas vezes, alaranjada. Em geral, o fruto contém apenas um caroço (putâmen ou pirênio) desenvolvido, porém, às vezes, pode conter até três ou quatro caroços (ARAÚJO, 1995; SILVA; MEDEIROS FILHO, 2006; OLIVEIRA, 2009).

O aproveitamento do fruto de pequi é praticamente integral: a casca é consumida em larga escala por animais bovinos; o caroço (com a polpa) é utilizado no preparo de pratos típicos; a polpa é utilizada ainda para extração e fabricação caseira ou industrial de óleo comestível, geleias, doces, licores e ração para alimentação animal; e a amêndoa é usada para consumo in natura, na extração de óleo e fabricação de sabão, e na indústria de cosméticos para fabricação de cremes e sabonetes (LORENZI, 1992; OLIVEIRA, 2009). A amêndoa, em função do seu elevado valor nutricional, formato, tamanho e da aparência visual, tem potencial para uso como mais uma opção no mercado nacional de amêndoas.

Em termos de valor nutricional, tem sido relatado na literatura que a polpa de pequi, espécie $C$. brasiliense Camb., apresenta em torno de 2,6 a 6,0\% de proteína; 26,07 a 33,4\% de lipídeos e de 7,75 a

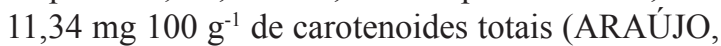
1995; LIMA et al., 2007; VERA et al., 2007). Já na espécie C. coriaceum Wittm., o estudo de Oliveira et al. (2010) revelou um teor de proteína de 2,09\% e de lipídeos de 23,19\%. A polpa de pequi também é rica em vitamina A e em minerais, especialmente $P$, $\mathrm{Ca}, \mathrm{Cu}$ e $\mathrm{Fe}$ (ARAÚJO, 1995).

Contudo, apesar de o fruto ser rico em nutrientes e das variedades de usos, o pequi, especialmente da espécie $C$. coriaceum, não tem merecido a devida atenção da pesquisa. Poucos são os estudos encontrados na literatura envolvendo a biometria (SILVA; MEDEIROS FILHO, 2006; OLIVEIRA, 2009) e a caracterização químiconutricional de frutos dessa espécie (OLIVEIRA et al., 2010). Mesmo diante do rápido avanço da fronteira agrícola e da urbanização sobre a vegetação nativa, pouco tem sido feito para que o germoplasma ainda existente dessa espécie e seu potencial de uso sejam conhecidos.

O objetivo deste trabalho foi avaliar a variabilidade de características físicas e químico-nutricionais de frutos de seis populações de pequizeiro de ocorrência natural nos Estados do Maranhão e Piauí. 


\section{MATERIAL E MÉTODOS}

\subsection{Coleta e localização da área de estudo}

O estudo abrangeu seis municípios: três no Estado do Maranhão (Timon, Caxias e Afonso Cunha) e três no Estado do Piauí (Alto Longá, Barras e José de Freitas), cada um correspondendo a uma população. A escolha desses municípios foi em função da facilidade de acesso e da elevada ocorrência do pequizeiro. Nas Tabelas 1 e 2, são apresentados dados de localização, bioma e alguns dados climáticos desses municípios.

Foram estudadas um total de 36 plantasmatrizes de pequizeiro, distribuídas nas seis populações: Alto Longá -8 plantas; Barras -5 plantas; José de Freitas -7 plantas; Afonso Cunha -5 plantas; Caxias -3 plantas; e Timon -8 plantas. Os critérios para escolha das plantas-matrizes dentro de cada população foram a presença de frutos maduros por ocasião das viagens de coleta e, da mesma forma que a escolha dos municípios, a facilidade de acesso.

A coleta dos frutos foi realizada no período da safra (fevereiro/março) de 2008, coletando-se frutos no estádio de maturação completa (frutos recémcaídos no chão). Por "recém-caídos", consideraramse frutos caídos no mesmo dia da coleta, cuja identificação foi feita observando-se o ponto de inserção do pedúnculo com o fruto (deve apresentarse sem oxidação ou, no máximo, levemente oxidado) e a presença de manchas amarronzadas (indicam que o fruto se encontrava no chão por um período de tempo mais longo). Depois de coletados, os frutos foram acondicionados em sacos plásticos e transportados para o Laboratório de Fisiologia Vegetal da Embrapa Meio-Norte, em Teresina-PI, onde foram armazenados em freezer $\left(-20^{\circ} \mathrm{C}\right)$ até o momento das medições físicas.

\subsection{Análises laboratoriais}

\subsubsection{Análises físicas}

As medições das características físicas dos frutos maduros foram realizadas no período de março a junho de 2008, utilizando amostra média de 15 frutos/planta. Foram tomadas as seguintes medidas físicas: massa média de fruto (MMF), massa média da casca (MMC), massa média do caroço (MMCa), massa média da amêndoa (MMA), percentagem de polpa (\%POLPA), relação comprimento de fruto/diâmetro médio de fruto (relação $\mathrm{CF} / \mathrm{DMF}$ ), relação comprimento do caroço/diâmetro médio do caroço (relação $\mathrm{CCa} / \mathrm{DMCa}$ ), relação comprimento da amêndoa/diâmetro médio da amêndoa (relação CA/DMA) e espessura média da casca (EMC). As medidas de massa foram obtidas em balança digital e expressas em gramas, e as dimensões foram obtidas com o auxílio de um paquímetro digital e expressas em centímetros.

\subsubsection{Análises químico-nutricionais}

As análises químico-nutricionais foram realizadas nos Laboratórios de Bromatologia da Embrapa Meio-Norte e no Centro de Ciências Agrárias da Universidade Federal do Piauí (CCA/ UFPI), em Teresina-PI, no período de agosto de 2008 a maio de 2009.

Após as medições físicas, os frutos foram descongelados e a polpa extraída manualmente, com o auxílio de faca de cozinha. Após o processo de extração, a polpa e os caroços foram secos em estufa de circulação forçada de ar à temperatura de $65^{\circ} \mathrm{C}$, até peso constante. As amêndoas, então, foram extraídas com o auxílio de um torno mecânico. A polpa e as amêndoas foram trituradas em processador, e as amostras, acondicionadas separadamente em embalagens plásticas emerticamente fechadas e novamente armazenadas em freezer $\left(-20^{\circ} \mathrm{C}\right)$ até o início das análises químico-nutricionais.

As seguintes características químiconutricionais foram analisadas: porcentagem de umidade (UMID), gordura (GORD), proteína bruta (PB), fibra bruta (FB), cinzas (CZ), carboidratos totais (CT), teor de energia (ENERG, expressa em kcal $\left.100 \mathrm{~g}^{-1}\right)$, e teor de minerais ( $\mathrm{P}, \mathrm{K}, \mathrm{Ca}, \mathrm{Mg}$, $\mathrm{Mn}, \mathrm{Cu}, \mathrm{Zn}$ e $\mathrm{Fe}$, expressos em MG $\left.100 \mathrm{~g}^{-1}\right)$. As medidas de GORD, PB, FB CZ, UMID e minerais foram obtidas de acordo com as normas analíticas do Instituto Adolfo Lutz (INSTITUTO ADOLFO LUTZ, 1985), e os teores de CT e ENERG conforme metodologia de Moretto et al. (2002).

\subsection{Análises dos dados}

As medidas das características físicas de fruto foram submetidas à análise de variância, considerando um delineamento estatístico inteiramente ao acaso, com seis tratamentos (populações) e frutos por planta sendo utilizados como medidas repetidas no mesmo indivíduo. Da mesma forma, para a análise de variância dos dados das análises químico-nutricionais, também se considerou um delineamento estatístico inteiramente ao acaso, com seis tratamentos (populações), porém com três repetições. As médias de populações foram comparadas por meio do teste de agrupamento ScottKnott, a 5\%. As análises foram realizadas utilizando o programa GENES (CRUZ, 2001). 


\section{RESULTADOS E DISCUSSÃO}

\subsection{Características físicas}

A análise de variância indicou efeito significativo de populações para todos os caracteres físicos de frutos estudados (Tabela 3).

A população de Alto Longá, no Piauí, foi a que apresentou as maiores médias de massa média do fruto (MMF), massa média da casca (MMC), massa média da amêndoa (MMA), relação comprimento/diâmetro médio do caroço (relação $\mathrm{CCa} / \mathrm{DMCa}$ ) e espessura média da casca (EMC), diferindo das demais populações $(\mathrm{P}<0,05)$, exceto da população de Timon em MMA. Por sua vez, as populações de Afonso Cunha e Caxias, ambas no Maranhão, obtiveram as menores médias para essas características.

Em relação à massa média do caroço (MMCa), a população de Timon, no Maranhão, e as populações do Piauí apresentaram as maiores médias. Por sua vez, as populações de Timon, Caxias e José de Freitas sobressaíram-se em porcentagem de polpa (\%POLPA). As populações de Timon, Caxias e José de Freitas também mostraram maiores médias para a relação comprimento/ diâmetro médio do fruto (relação $\mathrm{CF} / \mathrm{DMF}$ ), diferindo significativamente das demais populações. A população de Timon apresentou ainda a maior média para a relação CCa/DMCa. Vera et al. (2005, 2007), estudando populações de pequizeiros da espécie C. brasiliense do Estado de Goiás, também relataram diferenças entre populações para a maioria dos caracteres estudados.

Em geral, comparando os dados dos caracteres físicos avaliados com os dados de localização e climáticos dos municípios de ocorrência dos pequizeiros estudados (Tabelas $1 \mathrm{e}$ 2), não é possível estabelecer-se uma relação direta entre esses dados e os valores médios observados dos caracteres. Por exemplo, a população de Alto Longá, onde a precipitação é menor, especialmente no período de desenvolvimento dos frutos, mostrou maiores médias de MMF e MMA, enquanto a população de Caxias, onde há maior precipitação nesse período, mostrou médias menores desses caracteres. Esses resultados, portanto, indicam que a variabilidade observada entre as populações é devida majoritariamente a diferenças genéticas entre elas. É importante ressaltar, contudo, que os valores médios dos caracteres avaliados, bem como a variabilidade observada entre as populações, também são afetados pelo número de indivíduos avaliados por população. Neste aspecto, é muito provável que as médias obtidas para a população de Caxias estejam subestimadas em função do pequeno número de indivíduos avaliados.

Do ponto de vista do aproveitamento da polpa do fruto, maiores médias de MMC e MMCa não são desejáveis, pois nesta situação o teor de polpa tende a ser menor. Em geral, as populações do Piauí sobressaíram-se em relação às do Maranhão em MMF, porém houve predominância das populações do Maranhão em \%POLPA, já que as populações do Piauí apresentaram caracteres negativos, como maiores médias de MMC, MMCa e EMC (Tabela 3). Embora MMF isoladamente não permita fazer inferências sobre a capacidade de produção das populações, já que seria necessário saber-se o número de frutos/planta, maiores valores de MMF, em geral, indicam melhor qualidade do produto. Nesse aspecto, a população de Alto Longá, no Piauí, destaca-se das demais.

Em estudo de caracterização de frutos de pequi da espécie $C$. coriaceum, de ocorrência no Vale do Cariri-CE, Oliveira (2009) obteve MMF variando de 46,23 a 140,23 g, com média de 90,48 g, valores esses inferiores, portanto, aos obtidos neste trabalho. Da mesma forma, para MMA, essa autora obteve média de $1,56 \mathrm{~g}$, inferior à obtida no presente estudo $(1,85 \mathrm{~g})$, porém com maior amplitude de variação ( 0,86 a 2,68 g vs. 1,26 a 2,09 g). Por outro lado, no que se refere à \%POLPA, os resultados obtidos por essa autora (média de 10,52\% e variação de 5,99 a $14,57 \%$ ) foram bem superiores aos obtidos neste trabalho (média de 6,93\% e variação de 5,88 a 7,84\%). No entanto, a menor amplitude de variação obtida no presente estudo não indica, necessariamente, que a variabilidade presente nas populações de pequizeiro do Meio-Norte seja menor do que aquela detectada no Vale do Cariri-CE, uma vez que os resultados apresentados por Oliveira (2009) são de plantas individuais, ao contrário daquelas aqui apresentadas, as quais se referem a populações. Em outras palavras, os valores representam médias de vários indivíduos.

Em espécies perenes de propagação sexuada e assexuada, caso do pequizeiro, embora o melhoramento tenha como base a seleção fenotípica individual (que, no caso dessas espécies, é eficiente, permite ganhos rápidos e tem pouca ou nenhuma restrição quanto ao sistema reprodutivo), o uso de populações, em vez de plantas individuais, é importante em estudos de diversidade e de preservação, pois permite avaliar melhor a distribuição espacial da variabilidade.

\subsection{Características químico-nutricionais}

Os resultados das características químiconutricionais da polpa e da amêndoa das seis populações de pequizeiro estudadas estão apresentados nas 
Tabelas 4 e 5 .

Houve variação significativa entre populações para todas as características estudadas da polpa, exceto cinza $(\mathrm{CZ})$, e da amêndoa, exceto gordura (GORD) e energia (ENERG) (Tabela 4) e Mn (Tabela $5)$.

Na polpa, o teor médio de umidade (UMID) variou de 25,21\% (população de Timon-MA) a $37,91 \%$ (população de Afonso Cunha-MA), enquanto na amêndoa a variação foi de $47,62 \%$ (população de José de Freitas) a 53,21\% (população de Alto LongáPI), bem mais elevado, portanto, que a UMID da polpa. O valor médio de UMID da polpa $(31,51 \%)$ obtido neste trabalho foi bem inferior àqueles relatados por Oliveira et al. (2010), também para C. coriaceum (55,36\%), e Vera et al. (2007) e Mariano (2008) para C. brasiliense (51,25 e 48,48\%, respectivamente). Foi inferior também àqueles obtidos por Lima et al. (2007) e Gonçalves (2007) para C. brasiliense (41,5\% e 45,2\%, respectivamente). É possível que os baixos teores de umidade da polpa obtidos no presente trabalho se devam, em parte, à influência do congelamento (GONÇALVES, 2007). A população de Afonso Cunha, no Maranhão, apresentou a maior média $(3,05 \%)$ para o teor de cinzas $(\mathrm{CZ})$ na amêndoa. Observa-se que as médias de $\mathrm{CZ}$ na polpa e na amêndoa estão muito próximas e, em ambos os casos, não houve altas amplitudes de variação (Tabela 4). Outros trabalhos indicam valores inferiores de CZ na polpa e superiores na amêndoa (OLIVEIRA et al., 2010; LIMA et al, 2007; MARIANO et al., 2008). Em geral, em termos nutricionais, maiores teores de CZ significam maiores quantidades de minerais e, nesse aspecto, tanto a polpa quanto a amêndoa de pequi constituem-se em importantes fontes desses elementos (FRANCO, 1992).

Em relação ao teor de GORD da polpa, sobressaiu-se a população de Caxias, no Maranhão, com $38,09 \%$, seguida da população de Timon, também no Maranhão, com 35,16\%. Já na amêndoa, o teor médio de GORD foi 48,52\% superior ao teor médio da polpa, sem diferença significativa entre as populações (Tabela 4). Oliveira et al. (2010) também encontraram maior média de GORD na amêndoa de C. coriaceum. Contudo, as médias de GORD, tanto na polpa quanto na amêndoa obtidas neste trabalho, foram superiores àquelas obtidas por esses autores $(23,19 \%$ e $35,11 \%$, respectivamente) e equivalentes aos teores relatados por Lima et al. (2007) em $C$. brasiliense (33,4 e 51,51\%, respectivamente). No caso da polpa, a média de GORD (33,53\%) também foi superior às médias obtidas por Vera et al. (2007); um pouco inferior ao teor médio de $37,81 \%$ obtido por Mariano (2008) e bem inferior aos valores relatados por Gonçalves (2007) e Mariano-da-Silva et al. (2009), todos em C. brasiliense. É provável que diferenças de procedimentos metodológicos expliquem parte das discrepâncias nos teores de GORD entre os vários trabalhos.
As populações de Afonso Cunha, no Maranhão, e Barras, no Piaú, sobressaíram-se nos teores de proteína bruta $(\mathrm{PB})$ na polpa $(3,57 \%)$, enquanto a população de Alto Longá, no Piauí, sobressaiu-se em PB na amêndoa $(33,84 \%)$. Conforme pode ser observado pela Tabela 2, as médias de PB foram bem maiores na amêndoa. Resultados similares foram obtidos em $C$. brasiliense por Gonçalves (2007), Lima et al. (2007) e Mariano (2008). Contudo, o teor médio de PB na polpa, encontrado neste trabalho, foi cerca de $62 \%$ superior ao relatado por Oliveira et al. (2010) em seu estudo com C. coriaceum. O conteúdo de PB na amêndoa foi, em média, cerca de 10 vezes maior do que aquele obtido na polpa, indicando que a amêndoa de $C$. coriaceum é riquíssima em proteínas quando comparada com a polpa e, inclusive, com outras frutas tropicais (FRANCO, 1992) e, portanto, têm condições de ser mais bem aproveitada na alimentação humana.

As variações nos teores de fibra bruta (FB) da polpa e da amêndoa foram, aproximadamente, de mesma magnitude (Tabela 4) e indicam que a variabilidade presente nas populações estudadas possibilita ao melhorista lançar mão da seleção fenotípica individual de forma eficiente. As populações de Timon e Caxias, no Maranhão, destacaram-se nos teores de FB na polpa. Na amêndoa, por sua vez, a população de Afonso Cunha, também no Maranhão, teve a menor média. Os resultados obtidos neste estudo são inferiores aos relatados por Gonçalves (2007) e Lima et al. (2007) em FB na polpa, porém são um pouco superiores em FB na amêndoa.

A população de Afonso Cunha, no Maranhão, e as populações do Piauí obtiveram os maiores teores de carboidratos totais (CT) e de energia (ENERG) na polpa. Na amêndoa, a população de José de Freitas foi inferior às demais no teor de CT. Comparando os teores médios de CT e ENERG na polpa e na amêndoa, verifica-se que a polpa é mais rica em CT, e a amêndoa, em ENERG (Tabela 4). Esses resultados são importantes no aproveitamento mais completo do fruto na alimentação humana. Atualmente, apenas a polpa tem uso variado na culinária. A amêndoa tem uso mais indireto, na forma de óleo ou azeite de pequi (ARAÚJO, 1995). No entanto, pelo seu valor energético, aliado ao elevado teor proteico, poderia ser aproveitada para uso como amêndoa. Os teores médios de CT (57,83\%) e ENERG $\left(319,28 \mathrm{kcal}^{\left.100 \mathrm{~g}^{-1}\right)}\right.$ da polpa, obtidos neste estudo, são superiores aos teores médios desses nutrientes obtidos por Oliveira et al. (2010), também para C. coriaceum. Dessa forma, é importante a preservação das populações estudadas e, ao mesmo tempo, aproveitá-las no melhoramento do pequizeiro, visando a obter cultivares ou clones com frutos de melhor qualidade nutricional. Neste aspecto, as quatro populações mencionadas acima apresentam, em geral, maior potencial como fonte 
de genes para incrementar os teores de CT e ENERG na polpa. Contudo, em função do valor energético do fruto de $C$. brasilense bem maior (GONÇALVES, 2007; LIMA et al., 2007), a introdução de material genético dessa espécie talvez seja uma estratégia mais eficiente. Na amêndoa, as seis populações, exceto a de José de Freitas, são igualmente promissoras.

No que se refere aos teores de minerais (Tabela 5), observa-se que a amêndoa é bem mais rica que a polpa em praticamente todos os minerais analisados, o que reforça a necessidade de melhor aproveitamento da amêndoa na alimentação humana. As populações de Afonso Cunha, no Maranhão, e José de Freitas, no Piauí, destacaram-se das demais nos teores de P na polpa (105,9 e 96,28 mg $100 \mathrm{~g}^{-1}$, respectivamente). Na amêndoa, destacou-se a população de José de Freitas, com teor médio de 1.344,88 mg $100 \mathrm{~g}^{-1}$. A população de Alto Longá, no Piauí, destacou-se no teor de K na amêndoa (1.146,8 mg $100 \mathrm{~g}^{-1}$ ), enquanto as populações de José de Freitas, Alto Longá, Afonso Cunha e Timon tiveram maiores médias de $\mathrm{K}$ na polpa. Em $\mathrm{Ca}$ e $\mathrm{Mg}$ na polpa, destacaram-se as populações de Barras no primeiro

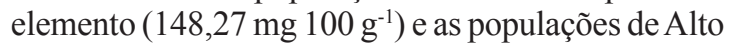
Longá (145,39 mg $\left.100 \mathrm{~g}^{-1}\right)$ e José de Freitas (147,46 mg $100 \mathrm{~g}^{-1}$ ) no segundo. Já na amêndoa, houve destaque das populações de Barras e Alto Longá (PI) e de Caxias e Timon (MA) nos teores de $\mathrm{Ca}$, e das populações de Alto Longá e José de Freitas (PI) e de Afonso Cunha (MA) em Mg.

Os teores médios de $\mathrm{P}, \mathrm{K}, \mathrm{Ca}$ e $\mathrm{Mg}$ na polpa e na amêndoa, obtidos no presente trabalho (Tabela 5), são maiores que os obtidos por Oliveira et al. (2010) em C. coriaceum da Chapada do Araripe-CE, porém são inferiores aos teores alcançados em C. brasiliense (MARIANO-DA-SILVA et al., 2009). Os teores médios de $\mathrm{P}$ e Ca na polpa são maiores também que os relatados em C. villsosum (MARX et al., 1997). $\mathrm{Na}$ amêndoa, os teores de $\mathrm{Ca}$ e Mg também superam os relatados na literatura para outras espécies de Caryocar. Esses resultados, portanto, evidenciam a presença de grande variabilidade genética para esses minerais no gênero Caryocar, o que aumenta as possibilidades de se obterem rápidos ganhos genéticos no melhoramento.

Em relação aos microelementos, as populações do Piauí sobressaíram-se nos teores de $\mathrm{Cu}$

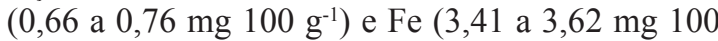
$\left.\mathrm{g}^{-1}\right)$ na polpa, com médias superiores às médias das populações. Já na amêndoa, também se sobressaíram as populações do Piauí nos teores de Mn (2,92 a 3,10 mg $\left.100 \mathrm{~g}^{-1}\right)$, enquanto a população de Afonso Cunha (MA) se sobressaiu no teor de Fe $\left(6,21 \mathrm{mg} 100 \mathrm{~g}^{-1}\right)$. As populações de Alto Longá e José de Freitas (PI) e Afonso Cunha (MA) destacaram-se em teor de $\mathrm{Cu}$, com médias de 4,73; 4,41 e 3,72 mg $100 \mathrm{~g}^{-1}$, respectivamente. Em Zn, apenas duas populações (José de Freitas e Caxias) mostraram teores estatisticamente inferiores aos das demais populações (Tabela 5).

Em termos médios, os resultados dos teores de $\mathrm{Zn}$ e Fe superaram os obtidos por Oliveira et al. (2010), em seu estudo também com C. coriaceum. Os teores de $\mathrm{Cu}$ e $\mathrm{Mn}$, por seu turno, ficaram abaixo dos obtidos por esses autores. Em C. brasiliense, Mariano-da-Silva et al. (2009) obtiveram teores de $\mathrm{Cu}$ e $\mathrm{Zn}$, de $\mathrm{Fe}$ e de $\mathrm{Mn}$, respectivamente, superiores, inferior e equivalente aos deste trabalho. $\mathrm{Na}$ amêndoa, os teores dos microelementos obtidos neste estudo, à exceção do $\mathrm{Cu}$, foram superiores aos relatados por Oliveira et al. (2010).

Em geral, os resultados apresentados e discutidos neste trabalho evidenciam que as populações de pequizeiro estudadas são portadoras de elevada variabilidade para a maioria dos caracteres analisados, não se evidenciando relação clara entre a variabilidade observada entre as populações e os dados de localização e clima dos locais de ocorrência. Essa variabilidade possibilita o aproveitamento de imediato das populações na seleção de indivíduos superiores e, também, em trabalhos de conservação in situ e ex situ. Nesse aspecto, as populações do Piauí mostram-se, de modo geral, mais promissoras, com destaque para os caracteres químico-nutricionais.

TABELA 1 - Dados de coordenadas geográficas, bioma e clima predominante dos municípios onde os frutos de pequi foram coletados.

\begin{tabular}{|c|c|c|c|c|}
\hline Municípios & Coordenads & as geográficas & Bioma & Clima predominante \\
\hline Afonso Cunha - MA & $4^{\circ} 07^{\prime} 59^{\prime \prime} \mathrm{S}$ & $43^{\circ} 19^{\prime} 25^{\prime \prime} \mathrm{W}$ & Cerrado & Tropical úmido \\
\hline Caxias - MA & $4^{\circ} 52^{\prime} 28^{\prime \prime} \mathrm{S}$ & $43^{\circ} 20^{\prime} 48^{\prime \prime} \mathrm{W}$ & Cerrado & Tropical úmido \\
\hline Timon - MA & $5^{\circ} 05^{\prime} 42^{\prime \prime} \mathrm{S}$ & $42^{\circ} 50^{\prime} 13^{\prime \prime} \mathrm{W}$ & Cerrado & Tropical úmido \\
\hline Alto Longá - PI & $5^{\circ} 15^{\prime} 04^{\prime \prime} \mathrm{S}$ & $42^{\circ} 12^{\prime} 32^{\prime \prime} \mathrm{W}$ & Caatinga & Tropical subúmido \\
\hline Barras - PI & $4^{\circ} 14^{\prime} 58^{\prime \prime} \mathrm{S}$ & $42^{\circ} 17^{\prime} 40^{\prime \prime} \mathrm{W}$ & errado, Caatinga & Tropical úmido \\
\hline José de Freitas - PI & $4^{\circ} 45^{\prime} 11^{\prime \prime} \mathrm{S}$ & $42^{\circ} 34^{\prime} 36^{\prime \prime} \mathrm{W}$ & errado, Caatinga & Tropical úmido \\
\hline
\end{tabular}

Fonte: IBGE, 2010. 
TABELA 2 - Dados de temperatura e precipitação pluviométrica dos municípios envolvidos no estudo, no período de floração e desenvolvimento dos frutos de pequi.

\begin{tabular}{cccccc}
\hline \multirow{2}{*}{ Municípios } & \multicolumn{2}{c}{ Temperatura $\left({ }^{\circ} \mathrm{C}\right)$} & \multicolumn{3}{c}{ Precipitação pluviométrica $(\mathrm{mm})$} \\
\cline { 2 - 6 } & $\begin{array}{c}\text { Média das } \\
\text { máximas }\end{array}$ & $\begin{array}{c}\text { Média das } \\
\text { mínimas }\end{array}$ & Ago/Set ${ }^{1}$ & Out/Dez & Jan/Mar ${ }^{3}$ \\
\hline Afonso Cunha - MA & 31,9 & 21,0 & 14,94 & 146,07 & 603,14 \\
Caxias - MA & 33,1 & 22,1 & 26,46 & 228,26 & 824,50 \\
Timon - MA & 33,6 & 22,3 & 19,19 & 203,61 & 753,20 \\
Alto Longá - PI & 31,5 & 20,6 & 5,69 & 100,79 & 542,12 \\
Barras - PI & 34,7 & 21,9 & 18,07 & 120,35 & 841,67 \\
José de Freitas - PI & 32,0 & 20,7 & 19,13 & 155,76 & 733,44 \\
\hline
\end{tabular}

Fonte: Agritempo, 2009

${ }_{1,2,3}$ Floração e frutificação, desenvolvimento e maturação dos frutos, respectivamente.

${ }^{4,5,6}$ Dados de estações mais próximas (Aldeias Altas-MA, Teresina-PI e São João da Serra-PI, respectivamente).

TABELA 3 - Características físicas de frutos de seis populações de pequizeiros de ocorrência nos Estados do Piauí e Maranhão.

\begin{tabular}{cccccccccc}
\hline \multirow{2}{*}{ Populações $^{1}$} & $\begin{array}{c}\text { MMF } \\
(\mathrm{g})\end{array}$ & \multicolumn{1}{c}{$\begin{array}{c}\text { MMC } \\
(\mathrm{g})\end{array}$} & $\begin{array}{c}\text { MMCa } \\
(\mathrm{g})\end{array}$ & $\begin{array}{c}\text { MMA } \\
(\mathrm{g})\end{array}$ & $\begin{array}{c}\text { \%OLPA } \\
\text { POF/DMF }\end{array}$ & $\begin{array}{c}\text { Relação } \\
\text { Ca/DMCação }\end{array}$ & $\begin{array}{c}\text { Relação } \\
\text { CA/DMA }\end{array}$ & $\begin{array}{c}\text { EMC } \\
(\mathrm{mm})\end{array}$ \\
\hline Afonso Cunha-MA & $140,7 \mathrm{c}$ & $97,0 \mathrm{c}$ & $19,5 \mathrm{~b}$ & $1,26 \mathrm{c}$ & $5,88 \mathrm{~b}$ & $0,52 \mathrm{~b}$ & $0,58 \mathrm{e}$ & $1,00 \mathrm{~b}$ & $9,86 \mathrm{~d}$ \\
Caxias-MA & $133,9 \mathrm{c}$ & $98,6 \mathrm{c}$ & $21,2 \mathrm{~b}$ & $1,88 \mathrm{~b}$ & $7,59 \mathrm{a}$ & $0,54 \mathrm{a}$ & $0,65 \mathrm{c}$ & $1,01 \mathrm{~b}$ & $9,87 \mathrm{~d}$ \\
Timon-MA & $153,7 \mathrm{~b}$ & $113,4 \mathrm{~b}$ & $25,7 \mathrm{a}$ & $2,07 \mathrm{a}$ & $7,84 \mathrm{a}$ & $0,54 \mathrm{a}$ & $0,69 \mathrm{a}$ & $1,01 \mathrm{~b}$ & $10,66 \mathrm{c}$ \\
Alto Longá-PI & $231,4 \mathrm{a}$ & $183,4 \mathrm{a}$ & $27,7 \mathrm{a}$ & $2,09 \mathrm{a}$ & $5,98 \mathrm{~b}$ & $0,52 \mathrm{~b}$ & $0,67 \mathrm{~b}$ & $1,06 \mathrm{a}$ & $14,24 \mathrm{a}$ \\
Barras-PI & $173,2 \mathrm{~b}$ & $131,5 \mathrm{~b}$ & $26,6 \mathrm{a}$ & $1,91 \mathrm{~b}$ & $5,74 \mathrm{~b}$ & $0,51 \mathrm{~b}$ & $0,63 \mathrm{~d}$ & $1,01 \mathrm{~b}$ & $12,07 \mathrm{~b}$ \\
José de Freitas-PI & $166,4 \mathrm{~b}$ & $124,2 \mathrm{~b}$ & $25,7 \mathrm{a}$ & $1,78 \mathrm{~b}$ & $7,29 \mathrm{a}$ & $0,53 \mathrm{a}$ & $0,64 \mathrm{~d}$ & $0,98 \mathrm{~b}$ & $10,90 \mathrm{c}$ \\
\hline Média & 173,30 & 133,91 & 25,90 & 1,85 & 6,93 & 0,53 & 0,67 & 1,01 & 11,84 \\
CV $(\%)$ & 29,81 & 33,64 & 23,95 & 28,76 & 25,10 & 7,51 & 4,21 & 10,81 & 19,49 \\
\hline
\end{tabular}

${ }^{1}$ Médias seguidas de mesma letra, nas colunas, não apresentam diferença estatística entre si, pelo teste de agrupamento Scott-Knott, a 5\%. MMF: Massa média do fruto; MMC: Massa média da casca; MMCa: Massa média do caroço; MMA: Massa média da amêndoa; CF: Comprimento do fruto; DMF: Diâmetro médio do fruto; CCa: Comprimento do caroço; DMCa: Diâmetro médio do caroço; CA: Comprimento da amêndoa; DMA: Diâmetro médio da semente; e EMC: Espessura média da casca.

TABELA 4 - Teores médios de umidade (UMID), cinzas (CZ), gordura (GORD), proteína bruta (PB), fibra bruta (FB), carboidratos totais (CT) e energia (ENERG) da polpa e da amêndoa de seis populações de Caryocar coriaceum da região Meio-Norte, Brasil.

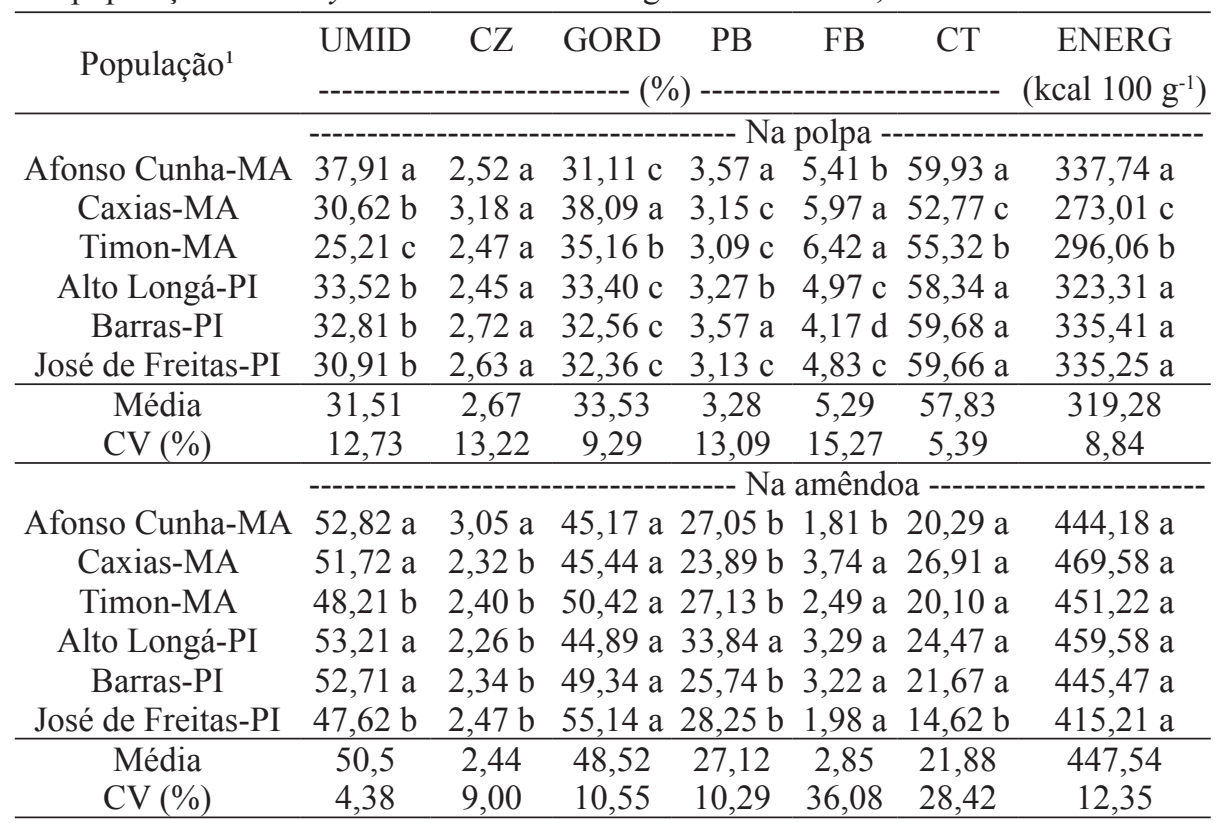

${ }^{1}$ Médias seguidas de mesma letra, nas colunas, não apresentam diferença estatística entre si, pelo teste de agrupamento Scott-Knott, a $5 \%$. 
TABELA 5 - Teores médios de minerais da polpa e da amêndoa de seis populações de Caryocar coriaceum de corrência na região Meio-Norte, Brasil.

\begin{tabular}{|c|c|c|c|c|c|c|c|c|}
\hline \multirow{2}{*}{ População ${ }^{1}$} & \multicolumn{4}{|c|}{ Macroelementos (mg $\left.100 \mathrm{~g}^{-1}\right)$} & \multicolumn{4}{|c|}{ Microelementos (mg $100 \mathrm{~g}^{-1}$ ) } \\
\hline & $\mathrm{Ca}$ & $\mathrm{P}$ & $\mathrm{K}$ & $\mathrm{Mg}$ & $\mathrm{Cu}$ & $\mathrm{Mn}$ & $\mathrm{Zn}$ & $\mathrm{Fe}$ \\
\hline & \multicolumn{8}{|c|}{ 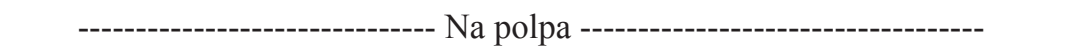 } \\
\hline Afonso Cunha-MA & $76,39 \mathrm{~b}$ & $105,90 \mathrm{a}$ & $487,06 \mathrm{a}$ & $86,09 \mathrm{c}$ & $0,43 \mathrm{~b}$ & $1,15 \mathrm{a}$ & $2,29 \mathrm{a}$ & $3,05 \mathrm{~b}$ \\
\hline Caxia & $103,65 \mathrm{~b}$ & $72,31 \mathrm{c}$ & $420,69 \mathrm{~b}$ & 130,5 & $0,53 \mathrm{~b}$ & $1,33 \mathrm{a}$ & $1,39 \mathrm{c}$ & $2,85 \mathrm{~b}$ \\
\hline Timo & $102,82 \mathrm{~b}$ & $84,03 \mathrm{~b}$ & 457,99 a & $122,08 \mathrm{~b}$ & $0,54 \mathrm{~b}$ & $1,21 \mathrm{a}$ & $1,91 \mathrm{~b}$ & $2,94 \mathrm{~b}$ \\
\hline Alto Long & $90,21 \mathrm{~b}$ & $90,04 \mathrm{~b}$ & $541,25 \mathrm{a}$ & & $0,76 \mathrm{a}$ & $1,63 \mathrm{a}$ & $2,16 \mathrm{a}$ & $3,41 \mathrm{a}$ \\
\hline & & & 345 & & $0,75 \mathrm{a}$ & & $1,45 \mathrm{c}$ & $3,62 \mathrm{a}$ \\
\hline José de $\mathrm{F}$ & $5 \mathrm{~b}$ & $96,28 \mathrm{a}$ & $554,67 \mathrm{a}$ & $6 \mathrm{a}$ & $0,66 \mathrm{a}$ & $1,71 \mathrm{a}$ & $1,35 \mathrm{c}$ & $3,49 \mathrm{a}$ \\
\hline & 101,99 & 83,55 & 460,43 & 124,6 & 0,58 & 1,31 & 1,75 & 3,12 \\
\hline $\mathrm{CV}(\%)$ & 18,85 & 9,04 & 16,74 & 10,06 & 19,91 & 29,11 & 7,71 & 6,53 \\
\hline \multicolumn{9}{|c|}{ 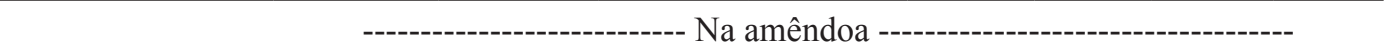 } \\
\hline Afonso Cunha-MA & $141,30 \mathrm{~b}$ & $1106,16 b$ & $989,44 \mathrm{~b}$ & $576,59 \mathrm{a}$ & $3,72 \mathrm{a}$ & $1,66 \mathrm{~b}$ & $6,20 \mathrm{a}$ & $6,21 \mathrm{a}$ \\
\hline Caxias & $177,90 \mathrm{a}$ & $886,74 \mathrm{c}$ & $980,97 \mathrm{~b}$ & $546,32 \mathrm{~b}$ & $2,86 \mathrm{~b}$ & $1,94 \mathrm{~b}$ & $4,97 \mathrm{~b}$ & $3,32 \mathrm{~b}$ \\
\hline Timon-MA & $170,17 \mathrm{a}$ & $977,06 \mathrm{c}$ & $926,78 \mathrm{~b}$ & $546,97 \mathrm{~b}$ & $1,80 \mathrm{~b}$ & $1,23 \mathrm{c}$ & $6,22 \mathrm{a}$ & $3,01 \mathrm{~b}$ \\
\hline Alto Longá-PI & $156,61 \mathrm{a}$ & $1221,86 \mathrm{~b}$ & $1146,80 \mathrm{a}$ & 604,57 a & $4,73 \mathrm{a}$ & $2,92 \mathrm{a}$ & $7,01 \mathrm{a}$ & $4,17 \mathrm{~b}$ \\
\hline Barras-PI & $181,66 \mathrm{a}$ & $698,48 \mathrm{~d}$ & $795,57 \mathrm{c}$ & $532,78 \mathrm{~b}$ & $2,86 \mathrm{~b}$ & $3,06 \mathrm{a}$ & $6,27 \mathrm{a}$ & $3,26 \mathrm{~b}$ \\
\hline José de Freitas-PI & $126,42 \mathrm{~b}$ & $1344,88 \mathrm{a}$ & $1021,13 \mathrm{~b}$ & $592,60 \mathrm{a}$ & $4,41 \mathrm{a}$ & $3,10 \mathrm{a}$ & $5,62 \mathrm{~b}$ & $3,97 \mathrm{~b}$ \\
\hline Média & 163,59 & 1008,45 & 965,67 & 560,01 & 2,98 & 2,03 & 5,97 & 3,70 \\
\hline $\mathrm{CV}(\%)$ & 8,50 & 8,81 & 8,93 & 5,27 & 34,93 & 15,24 & 12,26 & 20,28 \\
\hline
\end{tabular}

${ }^{1}$ Médias seguidas de mesma letra, nas colunas, não apresentam diferença estatística entre si, pelo teste de agrupamento Scott-Knott, a 5\%.

\section{CONCLUSÕES}

1-Há elevada variabilidade fenotípica nas populações de pequizeiro estudadas para a maioria dos caracteres físicos e químico-nutricionais do fruto, indicando que é possível o ganho genético por meio da seleção.

2-Ambas, a polpa e a amêndoa de pequi, são ricas em termos nutricionais, contudo a amêndoa destaca-se em minerais e em proteína bruta, constituindo uma excelente fonte de nutrientes para uso na alimentação humana.

3-A população de Alto Longá, no Piauí, obteve valores elevados para características importantes, como MMF e MMA; CT, ENERG, K, Mg, CU, Zn e $\mathrm{Fe}$, na polpa; e $\mathrm{PB}, \mathrm{FB}, \mathrm{Ca}, \mathrm{K}, \mathrm{Mg}, \mathrm{Cu}, \mathrm{Mn}$ e $\mathrm{Zn}$, na amêndoa, MMF e MMA sendo, portanto, uma fonte promissora de variabilidade.

4-As populações de pequizeiro de ocorrência no Estado do Maranhão apresentam, em geral, maior potencial em termos de teor de polpa.

\section{REFERÊNCIAS}

AGRITEMPO. Boletins regionais. Acesso aos produtos. Campinas: Embrapa Informática Agropecuária: Unicamp-Cepagri, 2009. Disponível em: <http:// www.agritempo.gov.br> Acesso em: 03 set. 2010.

ARAUJO, F.D. A review of Caryocar brasiliense (Caryocaraceae) - na economically valuable species of the central brazilian cerrados. Economic Botany, Bronx, v.49, n.1, p.40-48, 1995.

CRUZ, C.D. Programa GENES: aplicativo computacional em genética e estatística. Viçosa: UFV, 2001. 648p.

FRANCO, G. Nutrição: texto básico e tabelas de composição química dos alimentos. 9.ed. São Paulo: Atheneu, 1992, 178p.

GONÇALVES, G.A.S. Qualidade dos frutos do pequizeiro (Caryocar brasiliense Camb.) submetidos aos processos de congelamento e cozimento. 146f. 2007. Dissertação (Mestrado em Ciência e Tecnologia de Alimentos) - Universidade Federal de Lavras, Lavras, 2007. 
GRIBEL, R.; HAY, J.D. Pollination ecology of Caryocar brasiliense (Caryocaraceae) in Central Brazil cerrado vegetation. Journal of Tropical Ecology, Cambridge, v.9, p.199-211, 1993.

IBGE. Banco de dados. Cidades@. Disponível em: $<$ http://www.ibge.gov.br/cidadesat/topwindow. htm?1>. Acesso em: 03 set. 2010.

INSTITUTO ADOLFO LUTZ. Normas analíticas do Instituto Adolfo Lutz: métodos químicos e físicos para análise de alimentos. 3.ed. São Paulo: Instituto Adolfo Lutz, 1985. 533p.

LIMA, A.; SILVA, A.M.O.; TRINDADE, R.A.; TORRES, R.P.; MANCINI FILHO, J. Composição química e compostos biativos presentes na polpa e na amêndoa do pequi (Caryocar brasiliense Camb.) Revista Brasileira de Fruticultura, Jaboticabal, v.29, n.3, p.695-698, 2007.

LORENZI, H. Árvores brasileiras: manual de identificação e cultivo de plantas arbóreas nativas do Brasil. 4.ed. Nova Odessa: Plantarum, 1992. v.1, 368p.

MARIANO, R.G. de B. Extração do óleo da polpa de pequi (Caryocar brasiliense) por processos convencionais combinados com tecnologia enzimática. 2008. 70 f. Dissertação (Mestrado em Ciência e Tecnologia de Alimentos) - Universidade Federal Rural do Rio de Janeiro, Seropédica, 2008.

MARTINS, R.L; GRIBEL, R. Polinização de $\mathrm{Ca}$ ryocar villosum (Aubl.) Pers. (Caryocaraceae) uma árvore emergente da Amazônia Central. Revista Brasileira de Botânica, São Paulo, v. 30, n.1, p.3745, 2007.

MARX, F.; ANDRADE, E.H.A.; MAIA, J.G. Chemical composition of the fruit pulp of Caryocar villosum. Food Research and Technology, Berlin. v.204, p.442-444, 1997.

MORETTO, E.R. Introdução à ciência de alimentos. Florianópolis: UFSC, 2002. 255p.
OLIVEIRA, M.E.B. Características físicas, químicas e compostos bioativos em pequis (Caryocar coriaceum Wittm.) nativos da chapada do AraripeCE. 2009. 146f. Tese (Doutorado em Nutrição) Universidade Federal de Pernambuco, Recife, 2009.

OLIVEIRA, M.E.B; GUERRA, N.B.; MAIA, A. de H.N; ALVES, R.E.; MATOS, N.M. dos S.; SAMPAIO, F.G.M.; LOPES, M.M.T. Características químicas e físico-químicas de pequis da Chapada do Araripe, Ceará. Revista Brasileira de Fruticultura, Jaboticabal, v.32, n.1, p.114-125, 2010.

REBOUÇAS, A.C. Água na região Nordeste: desperdício e escassez. Estudos Avançados, São Paulo, v.11, n.29, p.127-154, 1997.

SILVA, M.A.P. da; MEDEIROS FILHO, S Morfologia de fruto, semente e plântula de pequi (Caryocar coriaceum Wittm.). Revista Ciência Agronômica, Fortaleza, v.37, n.3, p.320-325, 2006.

MARIANO-da-SILVA, S.; BRAIT, J.D. de A.; FARIA, F.P. de; SILVA, S.M. de; OLIVEIRA, S.L. de;BRAGA, P.F.; MARIANO-da-SILVA, F.M. de S. Chemical characteristics of pequi (Caryocar brasiliense $\mathbf{C a m b}$.) native of three municipalities in the State of Goias - Brazil. Ciência e Tecnologia de Alimentos, Campinas, v.29, n.4, p.771-777, 2009.

VERA, R.; NAVES, R.V.; NASCIMENTO, J.L.; CHAVES, L.J.; LEANDRO, W.M.; SOUZA, E.R.B. Caracterização física de frutos do pequizeiro (Caryocar brasiliense Camb.) no Estado de Goiás. Pesquisa Agropecuária Tropical, Goiânia, v.35, n.2, p.71-79, 2005.

VERA, R.; SOUZA, E.R.B. de; FERNANDES, E.P.; NAVES, R.V.; SOARES JUNIOR, M.S.; CALIARI, M.; XIMENES, P.A. Características físicas e químicas de frutos do pequizeiro (Caryocar brasiliense Camb) oriundos de duas regiões no Estado de Goiás, Brasil. Pesquisa Agropecuária Tropical, Goiânia, v.37, n.2, p.93-99, 2007. 